BBR 00407

\title{
CT-SCANNING IN CHILDREN WITH CEREBRAL VISUAL DISTURBANCE AND ITS POSSIBLE RELATION TO HYPOXIA AND ISCHAEMIA
}

\author{
O. VAN NIEUWENHUIZEN and J. WILLEMSE \\ Department of Child Neurology, University Hospital Utrecht, Utrecht (The Netherlands) \\ (Received September 4th, 1984) \\ (Revised version received September 18th, 1984) \\ (Accepted September 26th, 1984)
}

Key words: cerebral visual disturbance - infantile encephalopathy - computertomography - hypoxia/ischemia

\begin{abstract}
The examination of computertomography (CT) scans of 20 patients suffering from 'cerebral visual disturbance' (CVD) as part of infantile encephalopathy, revealed conspicuous abnormalities, which could be divided into two main groups: (1) lesions of the optic radiations; and (2) lesions of the calcarine cortex. The pathophysiological mechanisms underlying these abnormalities suggest an important role of hypoxia and/or ischaemia in the etiology of CVD.
\end{abstract}

\section{INTRODUCTION}

A high percentage of multiple handicapped children have in addition a visual handicap ${ }^{1,4,6}$. Woods $^{10}$, for example, examined 893 handicapped children at the Leeds Regional Child Assessment Centre between 1972 and 1977 and found a visual deficiency in 324 of them $(36 \%)$.

In a number of cases the cause of the visual impairment can be found by ophthalmological examination. However, in others no ophthalmological defect can be shown. In these cases the visual disturbance is usually assumed to be of cerebral origin: 'cerebral visual disturbance' (CVD), defined as a disturbance of vision caused by functional deficit of the retrochiasmatic part of the visual system.

CVD is not a rare occurrence. In a centre of multiple handicapped blind children (Bartiméushage, Doorn, The Netherlands) the incidence of CVD was $13 \%$ (out of $35 \%$ ). In general, two main causes of CVD can be distinguished: firstly, it may be due to progressive neurological diseases, such as metachromatic leukodystrophy; secondly, it may occur as part of infantile encephalopathy. The latter is defined as a permanent but not unchanging cerebral disorder, manifesting itself principally in defects of motor and sensory function with behavioural disorders; epilepsy and defective growth, due to a non-progressive defect or lesion of the brain in early life. Furthermore its association with hypoxic/ischaemic insult is well established $^{5}$.

The clinical diagnosis of CVD is usually based on the absence of ophthalmological defects. However as yet, we know little of the type or localization of the damage to central visual pathways thought to be the cause of the visual deficits.

In an attempt to relate visual impairment to anatomical structures, we report in this paper the findings from CT-scans of 20 patients suffering from CVD as part of infantile encephalopathy (some patients have been described previously ${ }^{9}$ ).

Examination of the CT-scans led to the following findings: in 11 patients dilatation of the occipital horns of the lateral ventricles was seen as well as

Correspondence: O. van Nieuwenhuizen, Department of Child Neurology, University Hospital Utrecht, Catherijnesingel 101, 3511 GV Utrecht, The Netherlands. 
atrophy of the calcarine cortex (Fig. 1). Six patients showed atrophy of the calcarine cortex only. Two patients showed dilatation of the occipital horns without cortical atrophy; one of them had isolated dilatation of the occipital horns while in the other the dilatation of the occipital horns was part of hydrocephaly (Fig. 2). No abnormalities were seen in the last patient.

The deviations, observed in our patients, have much in common with findings reported in studies of the immediate consequences of perinatal hypoxic/ischaemic events ${ }^{2,3,5,7,8}$ and seem to indicate the importance of hypoxia/ischaemia in the etiology of CVD (see also ref. 8).

\section{LESIONS OF THE OPTIC RADIATION}

With respect to dilatation of occipital horns, Pape and Wigglesworth ${ }^{5}$ stressed the significance of lesions caused by periventricular leukomalacia (PVL; defined as ischaemic infarction of the periventricular white matter) not only to motor tracks

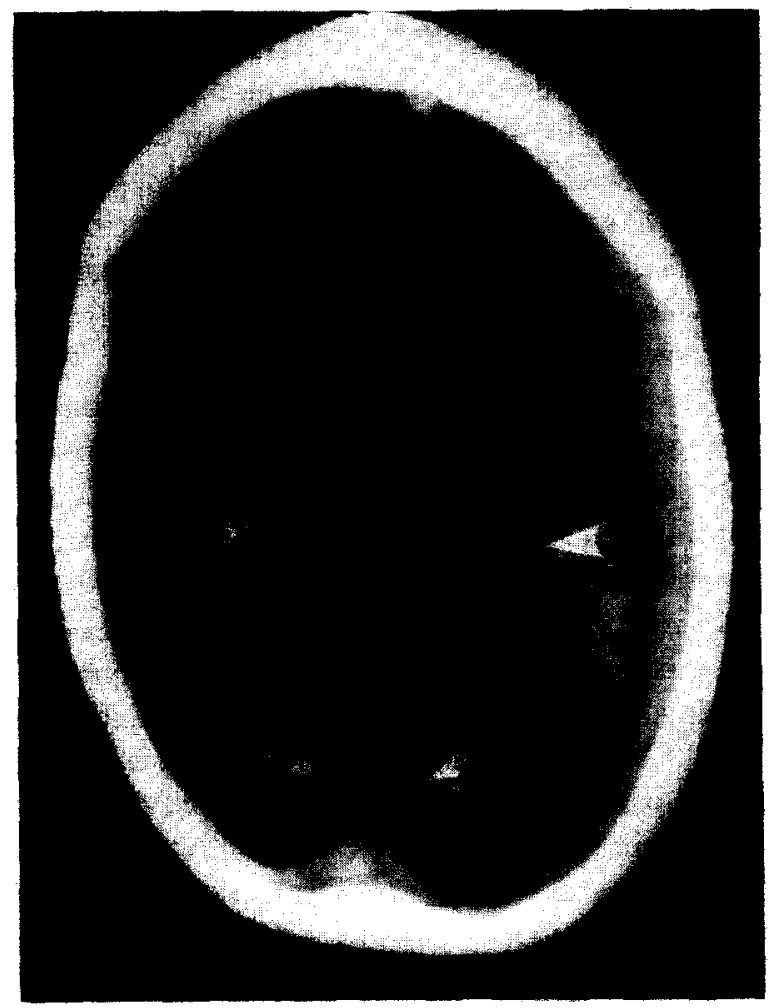

Fig. 1. Dilatation of the occipital horns (large arrows) as well as atrophy of the calcarine cortex (small arrows)

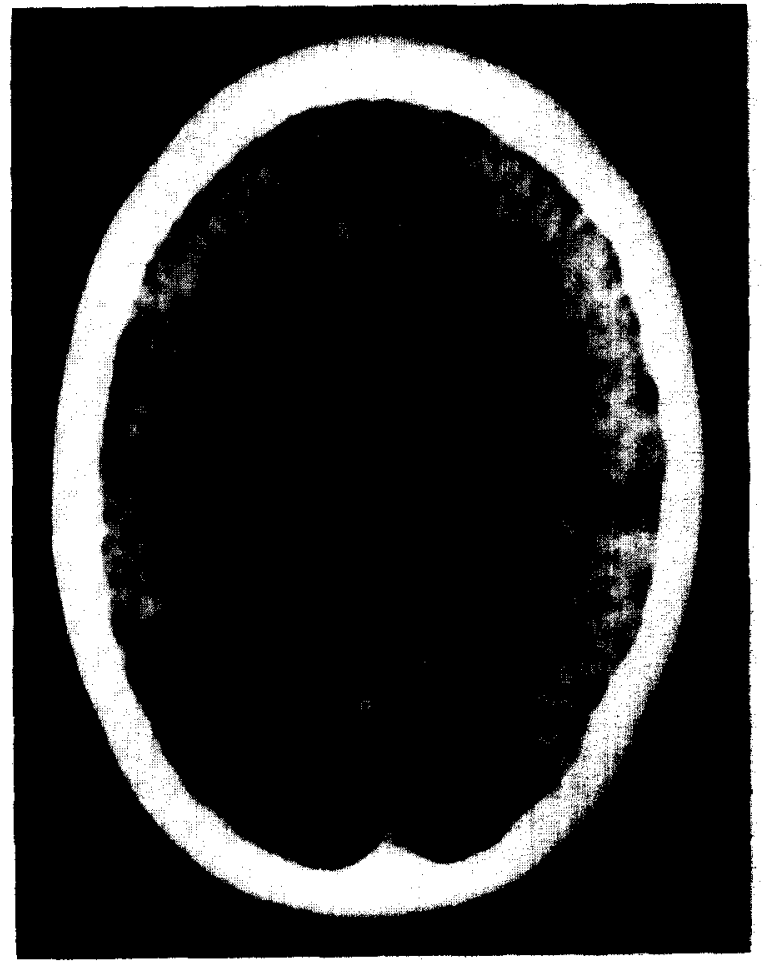

Fig. 2. Dilatation of the occipital horns (see arrows).

but also to optic radiations. The pathogenesis of this type of PVL was elucidated by the studies of De Reuck and Van der Eecken ${ }^{2}$, showing that PVL is more frequently found in the parietooccipital periventricular boundary zones in infants born after a gestation period of 35-40 weeks. Autopsy studies of 100 children who had suffered from PVL, showed damage of the optic radiations ${ }^{7}$.

In patients in whom PVL is very diffuse and extensive, atrophy of the periventricular white matter may occur causing dilatation of the occipital horns 'ex vacuo'. In other words: dilatation of occipital horns may indicate damage of optic radiations.

\section{LESIONS OF THE CALCARINE CORTEX}

With respect to cortical atrophy, the vulnerability of occipital poles to hypoxic/ischaemic lesions may be assumed, especially in the full term neonate ${ }^{3}$. These lesions can be demonstrated by CT-scanning as atrophy of the calcarine cortex. So, cortical atrophy may indicate damage of the 
calcarine cortex. The combination of cortical atrophy and dilatation of occipital horns is not uncommon ( 11 out of 20 patients) and may reflect the combination of PVL and cortical necrosis. This combination is more frequently found in the term infant ${ }^{5}$. Finally hydrocephaly may cause CVD since dilatation of occipital horns by pressure may lead to compression of optic radiations, causing functional deficit. In conclusion the abnormalities found in CT-scanning can be divided into two main groups: (1) lesions of the optic radiations; and (2) lesions of the calcarine cortex.

The demonstration of these findings in patients suffering from CVD may contribute to the understanding of underlying pathophysiological mechanisms and may suggest an important role of hypoxia and/or ischaemia in the etiology of CVD. CT-scanning may facilitate early diagnosis which opens up opportunities to medical and educational care of children suffering from CVD.

\section{ACKNOWLEDGEMENTS}

The authors thank Dr. J. van Hof-van Duin and Dr. G. Mohn for their constructive criticism. This study was supported by The Bartiméus Foundation, Doorn, The Netherlands.

\section{REFERENCES}

1 Black, P., Visual disorders associated with cerebral palsy, Brit. J. Ophthalmol., 66 (1982) 46-82.

2 De Reuck, J. and Van der Eecken, H., Brain maturation and types of perinatal hypoxic-ischaemic encephalopathy, Europ. Neurol., 22 (1983) 261-264.

3 Friede, R.L., Developmental Neuropathology, Springer, Wien, 1975 , p. 60.

4 Milot, J. and Guimond, J., Strabismus as an expression of cerebral motor dysfunction in childhood, Clin. Pediatrics, 16 (1977) 477-479.

5 Pape, K.E. and Wigglesworth, J.S., Haemorrhage, Ischaemia and the Perinatal Brain. Clinics in Developmental Medicine, Nos. 69/70. Spastics International Medical Publications London, 1979, pp. 103-107.

6 Robinson, R.O., The frequency of other handicaps in children with cerebral palsy, Develop. Med. Child Neurol., 15 (1973) 305-312.

7 Shuman, R.M. and Selednik, L.J., Periventricular leucomalacia; a one year autopsy study, Arch. Neurol., 37 (1980) 231-235.

8 Van Hof-van Duin, J. and Mohn, G., Visual defects in children after cerebral hypoxia, Behav. Brain Res., 14 (1984) 147-155

9 Van Nieuwenhuizen, O., Van Waes, P.F.G.M. and Willemse, J. Computerised tomographic abnormalities in children with cerebral visual disturbance, Lancet I (1983) 868-869.

10 Woods, G.E., Visual problems in the handicapped child, Child care hlth develop., 5 (1979) 303-322. 